\title{
Formação em Serviço Social, política social e envelhecimento populacional
}

Potyara A. P. Pereira*

Resumo: Este artigo relaciona política social e envelhecimento populacional como tema de interesse analítico atual das universidades. Detecta evidências empíricas que induzem esse interesse no âmbito mundial, dando destaque ao Serviço Social como área de conhecimento e ação. Na esteira dos desafios que o envelhecimento populacional coloca aos governos, sociedade e profissões, comenta os prós e os contras com que se depara o Serviço Social. Ao final, apresenta uma agenda para as políticas de atenção ao idoso e propostas de inserção do envelhecimento no processo de formação dos assistentes sociais.

Palavras-chave: envelhecimento populacional, política de atenção à pessoa idosa, formação universitária, Serviço Social.

Social Service formation, social policy and populational ageing

Abstract: This article relates social policy and populational ageing as the analytical current theme of interest in the

* Professora do Departamento de Serviço Social da Universidade de Brasília (UnB) e coordenadora do Núcleo de Estudos e Pesquisas em Política Social (Neppos), do Centro de Estudos Avançados Multidisciplinares (CEAM).

Comunicação apresentada, em Mesa Redonda, no Seminário sobre Educação Superior e Envelhecimento Populacional no Brasil, realizado nos dias 11 e 12 de maio de 2005, sob os auspícios do Ministério da Educação (MEC) SESU/CAPES. 
Universities. It detects empirical evidences that induce this interest in the world scope, highlighting the Social Work as the area of knowledge and action. In way of challenges that the populational ageing represent to governments, society and professions, it comments the pros and cons faced by the Social Work. Finally, it presents an agenda to attention policies for the elderly people and also proposal for the ageing insertion in the process of social workers formation.

Keywords: populational ageing, attention policy for the elderly people, university formation, Social Service.

\section{Introdução}

Várias são as evidências empíricas que atualmente induzem as universidades e, nestas, os cursos de Serviço Social, a se interessarem pelos conteúdos, metodologias e práticas de políticas sociais voltadas para o fenômeno do envelhecimento - isto é, para o espetacular aumento mundial das expectativas de vida da população.

Dentre essas evidências, três merecem destaque e podem ser assim sintetizadas:

a) o progressivo envelhecimento da população, ou o que alguns especialistas chamam de agrisalhamento demográfico, ou, ainda, a alvorada grisalha (gray dawn) (Peterson, apud Giddens, 2001), constitui um fenômeno sociopolítico inédito e sustentado, que produziu a seguinte reviravolta nos meios intelectuais e políticos contemporâneos: a partir do último quarto do século $\mathrm{XX}$, o interesse pelos assuntos gerontológicos tornou-se, pela primeira vez na história da humanidade, tão relevante, que suplantou o interesse pelos assuntos relacionados à 
infância e à adolescência que durou mais da metade daquele século;

b) o surgimento de novas necessidades decorrentes do fenômeno do envelhecimento e das condições estruturais e históricas em que esse fenômeno é produzido, traz à tona o entendimento de que essas necessidades dizem respeito não só à dimensão biológica, mas também psicológica, econômica, social e de cidadania das pessoas idosas;

c) o reconhecimento de que as políticas, os serviços, as instituições e os agentes de proteção social convencionais não mais respondem adequadamente a essas novas necessidades, exige a revisão dos compromissos com o bem-estar dessa parcela da população, tanto por parte do Estado quanto da sociedade.

Isso quer dizer que diante desse novo e cada vez mais visível fenômeno social, torna-se imperioso, no âmbito das universidades, a análise de seus determinantes, conseqüências, oportunidades e riscos, bem como a revisão de conceitos, critérios e objetivos capazes de subsidiar planejamentos e definições de políticas mais condizentes com a sua realidade. Só assim se poderá falar de uma comunidade acadêmica atualizada com o seu tempo e atenta ao compromisso com os direitos sociais que, no século $\mathrm{XX}$, constituíram as principais conquistas democráticas e as referências mestras da política social e do Serviço Social.

Afinal, a valorização do tema do envelhecimento está diretamente associada à recente multiplicação e diferenciação desses direitos que, no século XX, extrapolaram a convencional esfera privada dos cidadãos (civil e política), para abarcar a dimensão social da vida humana e incorporar novos titulares 
e garantias. Isso porque, com o adensamento da democracia, as pessoas deixaram de ser encaradas como cidadãs isoladas, abstratas, para serem vistas e tratadas "na especificidade ou na concreticidade de suas diversas maneiras de ser em sociedade, como criança, velho, doente, etc." (Bobbio, 1992, p. 68). Disso decorreu o respeito às diferenças de sexo, idade, étnico-racionais, de condições físicas e mentais, que não mais permitem tratamento e proteção iguais. Essas diferenças deram substância ao princípio da igualdade que, associado às liberdades positivas (por oposição às liberdades negadoras dos direitos sociais), incumbem ao Estado deveres de cidadania.

\section{O serviço social perante os prós e os contras do envelhecimento populacional}

Por ser uma profissão que atua em constante interação com as políticas e os direitos sociais, o Serviço Social não pode ficar alheio à tematização do fenômeno do envelhecimento. E mais, não pode se abster do exame crítico do significado e implicações contextuais desse fenômeno, visto que ele não se dá de forma isolada. O envelhecimento populacional é antes de tudo uma questão complexa. Está evidentemente ligado aos baixos índices de fecundidade, como ressalta EspingAndersen (2000); mas também tem relação com o avanço científico, especialmente no campo da saúde, assim como com as mudanças de valores e comportamentos que rompem cotidianamente com antigos estereótipos.

Só isso já é suficiente para que o Serviço Social procure atualizar o seu arsenal analítico e operativo, para, inclusive, subsidiar modificações nas políticas sociais. Mas nessa tarefa, não pode esquecer que, relacionados aos fenômenos e processos mencionados, há outros, estruturais, com suas inevitáveis conseqüências, que hoje mobilizam e desafiam 
os formuladores e executores de políticas, especialmente as dirigidas aos mais pobres.

Um deles, diz respeito ao fato de - desde os anos 1980 - o mundo viver sob a égide de um modelo socioeconômico global, denominado neoliberal, que é avesso à extensiva e autônoma realização de políticas sociais públicas, tal como aconteceu entre os "gloriosos" anos de 1945 a 1975, nas democracias centrais. Em vista disso, tem prevalecido, mundialmente, um tipo de regulação econômica e social, guiada pelo mercado, que não só restringe a participação do Estado na garantia de direitos, mas também cerceia a autonomia das nações para adotarem as políticas que melhor Ihes convenham. No rastro dessa nova regulação, impõe-se a exigência da flexibilização dos empregos e dos salários para enfrentar problemas inflacionários e a chamada crise fiscal do Estado, o que contribui para o aumento do desemprego e da desproteção social em geral.

Ocorre que o fenômeno do envelhecimento - com toda a sua pujança e necessidades -, se dá nesse contexto desfavorável à proteção social pública. E, como se não bastasse, se dá também num momento em que a família agora redescoberta como possível absorvedora de riscos criados por esse e outros fenômenos e processos - entre os quais o mau funcionamento do mercado de trabalho - está se reestruturando e não pode assumir cuidados e encargos como acontecia no passado. Pelo contrário, hoje a família também está exigindo maior tratamento analítico e segurança social, pois suas demandas e necessidades também são crescentes.

Em suma, as evidências empíricas permitem afirmar que os riscos sociais que decorrem das novas mudanças societárias - ou do advento da chamada sociedade pós-industrial - dizem respeito, principalmente, ao envelhecimento da população, à 
pobreza e desigualdade social causadas pelo desemprego estrutural, às mudanças na estrutura e nas funções da família (Cabrero, 1997), e à diminuição da proteção social pública.

Isso tem criado sérios dilemas para a política social contemporânea ao mesmo tempo em que impõe limites ao enfrentamento adequado dos referidos riscos pelo Serviço Social, embora não só a ele.

\section{Novos riscos sociais e o padrão de respostas governa- mentais}

Em face dos novos riscos sociais, todos os países do mundo, desde os tradicionalmente mais generosos, como os escandinavos, até os mais relutantes na prática extensiva da proteção social, como os Estados Unidos, têm concluído que não podem aumentar os gastos sociais perante demandas cada vez maiores, que tendem a se concentrar em duas áreas: i) na velhice, requerendo aumento de pensões e aposentadorias, além de despesas com saúde; e ii) no desemprego, exigindo uma variada gama de medidas de combate à pobreza e à ameaça de esgarçamento da coesão social. O problema é que essas demandas tendem a crescer continuamente, porque o envelhecimento apenas começou e a estabilidade do desemprego e da precarização do trabalho é uma realidade de difícil reversão.

Em vista desses fatos, os governos têm diminuído o seu compromisso com a efetivação de direitos sociais, seja elevando a idade para o acesso a aposentadorias, seja aumentando a carga tributária dos contribuintes ou, ainda, reduzindo o raio da proteção social pública, optando por políticas sociais focalizadas. Mas essas políticas sociais, ao restringirem o seu atendimento aos grupos mais pobres da 
população, deixam no desamparo segmentos socialmente vulneráveis que, por falta de recursos próprios, irão engrossar as fileiras dos mais pobres.

Este é o desafio do Benefício de Prestação Continuada (BPC), previsto na Constituição brasileira vigente $e$ regulamentado pela Lei oㅡ 8.742, de 7 de dezembro de 1993 (Lei Orgânica da Assistência Social - LOAS), que, desde 1994, transfere ao idoso e à pessoa portadora de deficiência pobres um salário mínimo mensal - enquanto perdurar sua condição de extrema necessidade. Embora esse benefício signifique um alívio material para idosos extremamente necessitados, que hoje atingem a casa dos 963.300 (a partir dos 65 anos de idade) e para 1.145.781 pessoas portadoras de deficiência severa, ele padece das fragilidades e irracionalidades inerentes às políticas sociais focalizadas na pobreza.

Isso indica uma caminhada (que não é só brasileira) em direção a um sistema de proteção social que, a despeito de minorar a situação de penúria de idosos e deficientes, não prioriza a sua condição de cidadão particular, ou a sua diversa maneira de ser em sociedade no dizer de Bobbio ( 1992, p. 68), mas a pobreza sobreposta à velhice e à deficiência. $E$ isso, apesar de meritório, não livra esses segmentos de dois produtos perversos das políticas sociais focalizadas: o estigma de assistido por incapacidade e a periódica submissão desse assistido a constrangedoras e dispendiosas comprovações de necessidades, em nome do controle de possíveis fraudes.

Ademais, apesar de a família atual não mais possuir condições de bancar a proteção de seus membros necessitados, ela vem sendo considerada uma inestimável fonte cuidadora de idosos, crianças e enfermos e, paradoxalmente, a base de cálculo das prestações sociais em detrimento do indivíduo e de seu carecimento particular. Isso sem falar da redução 
das necessidades dos beneficiários pobres à sua mais ínfima expressão, o que justifica o tratamento residual que lhe é freqüentemente dispensado.

São esses os mais visíveis dilemas das políticas sociais contemporâneas que incluem os idosos. Mas, no tocante a esse segmento, existem aspectos particulares que devem ser considerados como, por exemplo, o fato de a velhice não ser uma condição homogênea na qual se enquadrem todas as pessoas que atingem determinada idade. Ao contrário, trata-se de um "processo que se manifesta em fases e tempos e a cada uma dessas fases correspondem condições de vida e níveis de autonomia diferentes" (Juaréz, 1998, p. 450). Da mesma forma, não se deve esquecer que, apesar das limitações mencionadas, há variações nacionais no trato do fenômeno do envelhecimento, revelando maiores e menores preocupações com a autonomia e o bem-estar dos idosos.

Por isso, estudar o processo de envelhecimento torna-se uma tarefa complexa que também requer a particularização de condições, de necessidades, de exigências, de interesses e de possibilidades, de acordo com a classe social, o gênero e a etnia do idoso.

Por outro lado, em nome da eqüidade, faz-se necessário o aprofundamento analítico do fenômeno do envelhecimento, para uma atenção mais eficaz às situações particulares de mal-estar e marginalização sofridas por determinados grupos no contexto da atual transição demográfica (Juaréz, 1998, p.449). Por exemplo, já é reconhecido que "o envelhecimento é um fenômeno de gênero. As mulheres tendem a viver durante mais tempo do que os homens, fazendo da terceira idade uma idade altamente feminina" (Giddens, 2001, p. 167). Mas, o que poderia constituir vantagem do ponto de vista biológico, traz desvantagem do ponto de vista social. Devido à inserção 
ainda subalterna da força de trabalho feminina no mercado de trabalho, ou mesmo à dedicação integral de muitas mulheres ao lar, a maioria delas, quando idosas, enfrenta situações de empobrecimento, especialmente se depender dos esquemas focalizados de proteção públicos. Isso indica que esse segmento requer maior assistência e apoio, ao mesmo tempo em que denuncia implicações de gênero e classe social, quando não de etnia - já que as mulheres negras são ainda mais pobres e discriminadas - nos padrões de cuidados a serem prestados à população idosa.

Prosseguindo na identificação de particularidades, observa-se que, de modo geral, os idosos tendem a ser materialmente desfavorecidos em comparação com outros segmentos da população. A aposentadoria provoca queda de rendimentos, o que deteriora o padrão de vida desse segmento populacional, que, além disso, é o mais atingido pela inflação. No Brasil, estudos da Fundação Getúlio Vargas, divulgados em 11 de abril de 2005, mostram que, nas famílias onde há membros com mais de 60 anos, o Índice de Preços ao Consumidor da Terceira Idade tende a elevar-se, já que os produtos que pesam mais nessas famílias tiveram reajustes maiores, como: plano de saúde e remédios (que comprometem, respectivamente, $6,81 \%$ e $4,48 \%$ contra 3,70\% e 2,20\% da população em geral), hortaliças, frutas, pescado. Assim, enquanto de agosto de 1994 a dezembro de 2004, os reajustes para toda a população foram em média de $176,51 \%$, para as famílias com $50 \%$ dos seus membros idosos, esses reajustes alcançaram a média de 226,14\% (FGV, apud, Almeida, 2005).

Segundo o mesmo estudo, um outro fator de corrosão dos rendimentos dos idosos, no Brasil, são os gastos mais elevados com tarifas de telefone, água, luz e gás, que chegam a atingir $33 \%$ das despesas contra $30 \%$ referentes ao restante da família. Isso se explica pelo fato de os idosos ficarem mais 
tempo em casa e consumirem, com mais freqüência, esses serviços (FGV, apud Almeida 2005).

Do exposto, depreende-se que o envelhecimento é um processo que, ao mesmo tempo em que abre um leque de possibilidades de estudos e pesquisas, é também um desafio intelectual, social e político - além de ser uma experiência nova para quem atualmente a vivencia.

Hoje, apesar de inseridos em sociedades que majoritariamente valorizam a juventude e não serem mais considerados sábios, como acontecia nas culturas prémodernas e, atualmente, nas sociedades não ocidentais, como a Índia e a China (Giddens, 2001, p.165), os idosos estão se tornando uma força política. Constituem parte significativa dos eleitorados e muitos têm disposição para buscar autonomia, liberdade de movimentos e de participação. Grupos ativistas já começaram a combater a discriminação etária nos mesmos moldes em que são combatidos o racismo e a discriminação sexual. E propostas de criação de uma "sociedade sem idade", isto é, livre de classificações ou tipologias por faixa etária, que enquadram jovens, adultos e idosos em molduras fixas e estereotipadas, já circulam há algum tempo. O ideal defendem os adeptos dessas propostas - é que as pessoas sejam classificadas de acordo com suas características, iniciativas e identidades.

\section{Uma agenda necessária para as políticas de atenção aos idosos}

Torna-se, portanto, urgente pensar num perfil de políticas sociais que, a despeito das limitações impostas pelo modelo socioeconômico dominante, se baseie em análises (Juaréz, 1998): 
a) das condições de vida dos idosos, detectando mudanças nos planos pessoal e social;

b) das situações específicas de pobreza, mal-estar e marginalização a que muitos idosos estão submetidos;

c) dos fatores políticos, sociais, econômicos e culturais que influenciam as condições de vida dos idosos, com vista à revisão das políticas sociais vigentes $\mathrm{e}$ à proposição de outras novas;

d) das convergências e divergências dos esquemas de políticas sociais nacionais com os de outros países para, por meio da comparação e do contraste, retirar lições positivas.

Dentre as situações analisadas, uma assume importância fundamental para as políticas sociais brasileiras: a que é referente à pobreza, ao mal-estar e à marginalização dos idosos. Nessa situação particular deverão ser verificadas as condições de fato de sua existência, os processos e fatores que as determinam e os impactos que as políticas sociais tiveram, têm ou terão sobre a sua ocorrência.

De forma mais detalhada, isso implica considerar, em relação ao bem-estar dos idosos, pelo menos os seguintes indicadores:

- condições socioeconômicas de pobreza e marginalização;

- condições de habitabilidade e relações familiares;

- condições de saúde;

- acesso à educação como processo permanente;

- existência de solidariedade intergeracional (Juaréz, 1998); 
- serviços e benefícios sociais disponíveis e seus impactos, tendo como referência e objetivo a ampliação da cidadania;

- uso do tempo livre e participação em atividades culturais e sociopolíticas;

- perspectivas do futuro: exclusão ou pertencimento social?

Com base nesse quadro de possibilidades e desafios - ou de prós e contras - que interpela as universidades, é possível, no que tange aos cursos de Serviço Social, apresentar, em primeira aproximação, propostas de inclusão mais efetiva do tema do envelhecimento populacional em sua agenda de ensino, pesquisa e extensão.

\section{Propostas de incorporação do envelhecimento no processo de formação em Serviço Social}

É importante ressaltar que nos cursos de Serviço Social das universidades brasileiras, públicas e privadas, o interesse por este tema já foi despertado, constituindo objeto de análise e de práticas profissionais cada vez mais recorrentes. Essa tendência pode ser atestada com

- a criação de núcleos de estudos sobre o envelhecimento em vários departamentos;

- a oferta de cursos de pós-graduação lato sensu (especialização);

- o estabelecimento de linhas de pesquisa em programas de pós-graduação stricto sensu (mestrado e doutorado); e

- o tratamento analítico do tema em monografias de graduação e especialização, dissertações de mestrado e teses de doutorado. 
Confirma-se, assim, no âmbito do Serviço Social incluindo-se, aí, os espaços sociocupacionais da profissão -, a tendência mundial de valorização dos assuntos gerontológicos, reveladora da transferência de atenções antes concentradas na infância e na adolescência.

Entretanto, não há ainda nos cursos de Serviço Social brasileiros diretrizes e política de formação profissional para o atendimento do idoso tal como previsto na Portaria $n^{\circ} 56$, de 25 de novembro de 2004, da Secretaria de Ensino Superior (SESu), do Ministério da Educação, que, em seu enunciado e no art. 1ㅇ, assim dispõe: "O Secretário de Educação Superior do Ministério da Educação, no uso de suas atribuições legais resolve: art. 1ํ - Criar Comissão Especial com a finalidade de elaborar diretrizes e propor políticas para a formação de profissionais aptos ao atendimento do idoso".

Também não há, nos termos da referida Portaria, inclusão dessa matéria nas diretrizes curriculares vigentes dos cursos de Serviço Social e também não há, em âmbito nacional, uma política abrangente e concertada de estudos e discussões nessa área.

Sendo assim, como inserir de forma mais efetiva a temática do envelhecimento na pauta de ensino, pesquisa e extensão dos cursos de Serviço Social brasileiros, aproveitando-se, inclusive, o atual processo de revisão curricular nas unidades de ensino?

Um passo nesse sentido poderia ser a inclusão, no rol das chamadas políticas sociais especiais, que, tanto na graduação como na pós-graduação, constituem disciplinas optativas, a temática do envelhecimento associada à questão da diminuição da fecundidade. Trata-se, nesse caso, de contextualizar o fenômeno no atual processo da transição demográfica e de suas conseqüências presentes e futuras. 
Aliás, as questões demográficas, hoje tão influentes nos rumos da política social, têm se mantido ausentes dos currículos do Serviço Social.

Além disso, pelo fato de o envelhecimento ter caráter multidisciplinar e perpassar o conteúdo de várias disciplinas, como as referentes à família, à assistência social, à saúde, à educação, ao trabalho, à previdência, elas poderiam contemplar em suas ementas referências particulares aos idosos.

Ainda no âmbito do ensino, é possível criar tópicos especiais ou módulos livres que dêem conta de assuntos emergentes, ou não previstos formalmente, sobre o envelhecimento, e oferecê-los de acordo com um plano previamente elaborado e aprovado pelos colegiados departamentais. Isso sem falar dos estágios curriculares, realizados em instituições credenciadas onde os alunos vivenciam práticas profissionais nos mais diferentes campos, incluindo à atenção aos idosos. Essas práticas, que normalmente são realizadas sob a dupla supervisão de um profissional de campo e de um professor responsável pela disciplina, também poderiam ocorrer em locais que desenvolvam políticas e cuidados, de qualidade reconhecida, à chamada terceira idade. Isso, além abrir um canal de aprendizagens recíprocas - acadêmicas e operativas - contribuirá para maior inter-relação entre universidade e comunidade externa.

No campo da pesquisa, os cursos de Serviço Social deverão primar por um processo de formação profissional em que a investigação seja uma atividade permanente. Mas, de par com o ensino de metodologias apropriadas, a seleção de temáticas relevantes e atuais deverá constituir preocupação básica. Assim, um tema social como o envelhecimento, que se impõe ao estudo e à investigação pelo seu caráter revolucionário, não poderá deixar de ser contemplado nos 
projetos de pesquisa de professores e alunos de Serviço Social. Até porque são esses estudos e pesquisas que irão subsidiar a elaboração de diagnósticos da realidade a ser trabalhada pelo profissional e a definição de políticas sociais coerentes e consistentes com essa realidade.

Isso justifica que os Departamentos, criem núcleos ou grupos de estudos dessa temática, a serem credenciados em órgãos de fomento à pesquisa, como o CNPq, nos quais tanto alunos de graduação como de pós-graduação possam participar de projetos coordenados por professores, ou desenvolver, dentro desses projetos, planos individuais de trabalho em função de suas monografias de graduação, dissertações de mestrado e teses de doutorado.

Tal procedimento poderá contribuir para fortalecer os estudos isolados já existentes no Serviço Social e criar condições para a instituição de pesquisas integradas nos âmbitos local, nacional e internacional, em consonância com uma política de investigação permanente e abrangente nesta área. Com esse mesmo objetivo, estudos sobre o envelhecimento populacional realizados por outros departamentos ou núcleos de estudos dentro das universidades deverão ser articulados pelos Departamentos de Serviço Social não só para compartilharem e somarem seus achados científicos, mas também para fortalecerem a abordagem multidisciplinar dessa temática.

Entretanto, como o Serviço Social é uma profissão interventiva, suas pesquisas devem ter como meta não apenas o conhecimento da realidade, mas principalmente o uso desse conhecimento para fomentar mudanças socialmente necessárias dessa ou nessa realidade. Nesse sentido, a pesquisa sobre o fenômeno do envelhecimento a ser realizada pelo Serviço Social não constituirá um fim em si mesma, mas um meio capaz de subsidiar ações ou políticas planejadas e intencionais. 
Por fim, para que os resultados das pesquisas realizadas não fiquem confinados aos círculos intelectuais, profissionais $e$ políticos especializados, é importante que os Departamentos de Serviço Social encontrem formas de divulgarem o mais amplamente possível esses resultados, cumprindo, assim, com a finalidade urgente de transformar o fenômeno do envelhecimento em uma questão pública.

Quanto à extensão, diversas são as formas de tratar o tema do envelhecimento, seja mediante atividades pontuais, seja mediante projetos de ação contínua. Nas atividades pontuais, podem ser incluídos cursos de curta duração, seminários nacionais e internacionais, ciclos de palestras, atendimentos emergenciais, consultorias, intercâmbios institucionais. E nos projetos de ação contínua, podem ser realizados experiências e trabalhos de média e longa duração, fora dos muros da universidade, com a participação de voluntários e envolvendo comunidades ou instituições específicas.

Para ter repercussão positiva, a extensão não deve se desligar do ensino e da pesquisa, com os quais compõe, organicamente, as três funções básicas da universidade, nem deixar de fazer parte de uma política de formação profissional que cerque o fenômeno do envelhecimento em sua complexidade e totalidade.

Sabe-se que colocar em prática essas propostas não é fácil, principalmente se levadas em conta as dificuldades por que passam as universidades. Porém, quanto mais cedo os cursos de Serviço Social se conscientizarem de seu papel histórico no trato desse processo irreversível, menos problemática será a sua atualização e menos tardia a sua contribuição à sociedade. 


\section{Referências}

ALMEIDA, Cássia. O peso da idade no bolso. O Globo [jornal], seção Economia, 12 abr. 2005.

BOBBIO, Norberto. A era dos direitos. Rio de Janeiro: Campus, 1992

BRASIL. Ministério da Educação (MEC). Secretaria de Educação Superior (SESu). Portaria ํㅡ 56, de 25 de novembro de 2004. Diário Oficial da União, 26 nov. 2004.

CABRERO, Gregório R. Por um nuevo contrato social: el desarrollo de la reforma social em el âmbito de la Unión Europea. In: MORENO, Luís (Comp.). Unión Europea y Estado del Bienestar. Madrid: CSIC, 1997.

ESPING-ANDERSON. Fundamentos sociales de las economias postindustriales. Barcelona: Editorial Ariel, 2000.

GIDDENS, Anthony. Sociologia. 4. ed. Lisboa: Fundação Calouste Gulbenkian, 2004.

JUARÉZ, Miguel. Política social para personas mayores. In: BRACHO, Carmén, A.; FERRER, Jorge G. Política social. Madrid: McGrawHill, 1998.

PEREIRA, Potyara A. P. Mudanças estruturais, política social e o papel da família. In: SALES, Mione A.; MATOS, Maurílio C.; LEAL, Maria Cristina (Org.). Política social, família e juventude: uma questão de direitos. São Paulo: Cortez; Rio de Janeiro: UERJ, 2004.

SCORTEGAGNA, Renzo. Nuevos servicios y nuevas aproximaciones en la política social para los ancianos. In: SARASA, Sebastià; MORENO, Luís. El Estado del Bienestar en la Europa del Sur. Madrid: CSIC, 1995.

WALKER, Alan. Older people. In: ALCOCK, Pete et al. (Ed.). The student's companion to social policy. Oxford: Blackwell, 1998. 